\title{
La educación para una ciudadanía democrática en las instituciones educativas: Su abordaje sociopedagógico
}

\section{Education for Democratic Citizenship in Educational Institutions: The Socio-educational Approach}

\author{
Arturo Torres Bugdud \\ Facultad de Ingeniería Mecánica y Eléctrica \\ Universidad Autónoma de Nuevo León \\ México \\ atorres85@hotmail.com \\ Nivia Álvarez Aguilar ${ }^{2}$ \\ Facultad de Ingeniería Mecánica y Eléctrica \\ Universidad Autónoma de Nuevo León \\ México \\ nivial12@yahoo.es \\ María del Roble Obando Rodríguez ${ }^{3}$ \\ Facultad de Ciencias de la Comunicación \\ Universidad Autónoma de Nuevo León \\ México \\ maroba215@hotmail.com
}

Recibido 20 de mayo de 2012 • Corregido 17 de junio de 2013 • Aceptado 19 de junio de 2013

$1 \quad$ Ingeniero mecánico y eléctrico. Maestrías en Administración y en Enseñanza de las Ciencias. Doctor en Ciencias Pedagógicas. Es miembro del Sistema Nacional de Investigadores de México (SNI). Actualmente subdirector de Desarrollo Humano en FIME. Ha publicado varios artículos en revistas de prestigio internacional sobre formación del profesorado y formación integral del estudiantado. Lidera el cuerpo académico sobre gestión educativa. Es evaluador externo de dos revistas indexadas. Ha presentado numerosos trabajos en congresos nacionales e internacionales.

2 Doctora en Ciencias Pedagógicas, Minsk, Bielorrusia. Profesora titular A de la Facultad de Ingeniería Mecánica y Eléctrica, UANL, Mèxico. Profesora consultante del Centro de Estudios de Ciencias de la Educación de la Universidad de Camagüey, Cuba. Ha escrito varios libros y artículos sobre temas educativos en diferentes revistas arbitradas e indexadas. Ha asesorado varias tesis de maestría y doctorado sobre diferentes temas de pedagogía y didáctica. Ha presentado varios trabajos en eventos nacionales e internacionales. Evaluadora externa de las revistas Educación y Futuro (España) y Matices ( México) y Educare ( Costa Rica).

3 Maestra en Enseñanza Superior. Coordinadora de la Maestría Profesionalizante. Catedrática de la Facultad de Ciencias de la Comunicación de la UANL, titular del cuerpo académico de Estudios de Comunicación, Formación, Administración y Cultura, colaboradora del CA Gestión Académico- Administrativa, cuenta con reconocimiento Perfil PROMEP. Asesora de la Dirección de Posgrado de la UANL. Ha publicado artículos en diferentes revistas y presentado múltiples trabajos en eventos nacionales e internacionales. 
URL: http://www.una.ac.cr/educare

CORREO: educare@una.cr

Resumen. La educación ciudadana es uno de los temas educativos de mayor actualidad, además de abordar aspectos esenciales de la dimensión personal y social del estudiante, posee puntos de contacto importantes con otras direcciones de la práctica educativa. En este artículo se enfatiza la democracia como cualidad importante de la educación ciudadana que requiere especial atención en su abordaje sociopedagógico. El tema de la educación ciudadana se afronta por diferentes disciplinas científicas, en este caso se acentúa el enfoque pedagógico desde una perspectiva social. El objetivo fundamental de este artículo de reflexión es argumentar los sustentos teóricos sobre esta temática, a través de estudios realizados en diferentes contextos desde el campo de las ciencias sociales, destacando la importancia que adquiere la educación ciudadana en la actualidad, independientemente del nivel educativo en el que se lleve a cabo. Para el cumplimiento del citado objetivo se usaron el método histórico-lógico y análisis-síntesis para valorar los antecedentes del tema abordado y de allí aportar elementos claves para su posible concreción en las instituciones educativas.

Palabras claves. Educación ciudadana, democracia, abordaje sociopedagógico de la educación ciudadana, enfoque pedagógico.

Abstract. Citizenship education is one of the most relevant topics in education. It comprises key aspects of the student's personal and social behavior, and has significant points of convergence with other areas of the educational practice. Democracy is emphasized in this paper as an important feature of citizenship education, which requires special attention in terms of its socio-educational approach. Citizenship education may be studied from different scientific disciplines; in this case, the pedagogical approach is studied from the social perspective. The main objective of this paper is to discuss the theoretical basis on the subject matter of this project, through studies conducted in different contexts of the social sciences, underlining the importance of citizenship education today, regardless of the educational level in which it is taught. Analysis-synthesis and historicallogical methods were used to assess the background on the subject, obtaining results that could be developed in the educational institutions, in the future.

Keywords. Citizenship education, democracy, socio-educational approach of citizenship education, pedagogical approach.

El desarrollo científico-técnico es un logro de la humanidad innegable; sin embargo, es de consenso que los cambios vertiginosos en este campo han traído también efectos indeseables para la sociedad, entre otras cuestiones, por la disminución de la interdependencia directa entre las personas, al aumentar la mediación de las máquinas en las relaciones personales. Estos cambios irreversibles deben complementarse con prácticas educativas donde se propicien las relaciones sociales encaminadas a potenciar la valoración constante de los deberes y derechos de la ciudadanía.

Por otra parte, las instituciones educativas deben reafirmar su papel de primer orden en la formación ciudadana, abierta a todos los alumnos y alumnas sin discriminación, integrando el reconocimiento de la diversidad sociocultural con las diferencias individuales. Se pretende, así, la consecución de objetivos orientados a la igualdad de derechos y al reconocimiento de las diferencias, así como a la consideración y desarrollo de la capacidad y responsabilidad del estudiantado para participar activamente en la transformación de la sociedad. 
La educación ciudadana, también enunciada como educación para la ciudadanía (UNESCO, 2000), muestra miradas múltiples que disienten en determinados aspectos, pero en muchos de ellos resultan convergentes. En la bibliografía especializada se encuentra el tratamiento de este tema con distintos términos: educación cívica y educación para la democracia. Sin embargo, en este trabajo no se identifica educación cívica con educación ciudadana, por cuanto se le adjudica un sentido más amplio. También se considera impreciso identificar la educación ciudadana con educación democrática, por cuanto la educación ciudadana es un concepto más amplio. Sin embargo, los autores concuerdan en que pudiera ser adecuado el uso de los términos: educación ciudadana democrática o educación para una ciudadanía democrática.

En algunos países existe la asignatura Educación para la Ciudadanía ${ }^{4}$, igualmente se ha trabajado como un eje transversal'; ; en otros se imparte con la denominación de Educación Cívica ${ }^{6}$. Vale aclarar que el presente estudio postula este concepto con un significado amplio, sin circunscribirse a una determinada asignatura que entre sus componentes fundamentales contiene la democracia y es educable, tanto en el proceso de enseñanza aprendizaje como en otras actividades dentro de la escuela y fuera de ella. Solo mediante una participación ciudadana de naturaleza democrática, comprendida como una "actitud ante la vida", es posible la evolución personal y social.

Se comparte con Baeza-Correa (2013), en que el entramado social se ha vuelto más frágil y el concepto de comunidad se ha resquebrajado, o quizás dicho de otra forma, ha perdido atención puesto que los ciudadanos difícilmente se ven a sí mismos formando parte de un sujeto colectivo, de un "nosotros", que acrecienta los riesgos de una sociedad fragmentada, lo que otorga una nueva importancia a la cuestión de la cohesión entre las instituciones educativas y el contexto social. Frecuentemente, dichas instituciones se centran en sí mismas, lo que acarrea, como consecuencia, una marcada indiferencia y desconocimiento de diferentes factores sociales que influyen en la formación de los estudiantes.

Relacionado con lo anterior, la Comisión Económica para América Latina y el Caribe CEPAL- (2007), refiriéndose a cohesión social (inclusión y sentido de pertenencia en América Latina y el Caribe), sostiene que en toda esta situación, paradójicamente, es la juventud, en especial, quien sufre las mayores dificultades (desde luego los jóvenes y las jóvenes más pobres), pues pese a que este grupo se encuentra hoy más incorporado a los procesos formales de adquisición de conocimientos y formación de capital humano -aunque de manera desigual de acuerdo con los ingresos-, se encuentra más excluido de los espacios en que dicho capital humano puede concretarse.

El tema de la educación ciudadana en el ámbito educativo ha cobrado especial interés desde la última década del pasado siglo y, especialmente, en el comienzo del presente,

4 En diferentes países de Europa como Alemania, Francia y España.

5 En España se introduce una asignatura con este nombre en el currículo escolar en el 2007.

6 Es el caso de Cuba y México, entre otros. 
URL: http://www.una.ac.cr/educare

CORREO: educare@una.cr

tanto a nivel de cada país, como en Gonzs internacionales. Es obvio que ante los desafíos actuales que enfrentan nuestros países en materia de cultura política y democratización de los espacios públicos y privados, emerge una tendencia de educación ciudadana que privilegia la formación para la acción transformadora desde una perspectiva crítica y contextualizada (Conde, 2007).

La educación ciudadana en las sociedades latinoamericanas en general está llamada a desarrollar una educación para el cambio en relación con los grandes problemas que enfrentamos; de este modo, la educación ciudadana de jóvenes y adultos se pudiera convertir en una propuesta pedagógicamente real, solamente si parte de los problemas cotidianos y específicos de cada realidad y cada contexto, de modo tal que posea significado y sentido en la vida cotidiana del estudiantado.

El objetivo principal del siguiente artículo de reflexión es la argumentación de las bases teóricas sobre la educación para una ciudadanía democrática desde su abordaje sociopedagógico, lo que permitirá su concreción en la práctica educativa escolar.

Consta de 4 aspectos fundamentales que exponen los fundamentos epistemológicos de la educación ciudadana democrática: se esclarecen diferentes posiciones de los autores; se exponen las principales concepciones sociopedagógicas de ciudadanía y democracia, y se enfatiza el significado y sentido de estos conceptos tanto para las instituciones educativas como para la sociedad en general; se aportan los criterios de los autores que promueven la democracia como cualidad esencial de la educación ciudadana y, por último, se fundamentan aspectos importantes sobre el abordaje pedagógico de la democracia, cuestión insuficientemente tratada en la bibliografía al respecto.

\section{Fundamentos epistemológicos que sustentan la educación ciudadana democrática}

Es insuficiente la comprensión tanto por parte de quienes trazan las políticas educativas como por los directivos y docentes de las instituciones escolares y extraescolares, acerca de que el proceso educativo requiere hoy más que nunca su acercamiento a la vida social. Si se está de acuerdo en que la educación es el factor más poderoso en la formación del ser humano, entonces no se puede eludir su compromiso, ni ponerlo en manos de otros factores y agentes. Por esta razón, la educación ciudadana desde las instituciones educativas es una urgencia impostergable para la solución a los graves problemas que afronta la sociedad actual.

Se coincide con Caruso (2007) acerca de que el concepto de ciudadanía no es sencillo; es polisémico, es polivalente, en algunos casos, incluso es confuso y está ligado a los objetivos y al marco del pensamiento de las personas o grupos que lo proponen. Un punto de partida sería la definición de ciudadano o ciudadana como alguien que vive en una nación, se naturalizó en algún país y es sujeto de ciertos derechos; esta idea, si bien extremadamente simple es la que se identifica por la mayoría de las personas. 
Lógicamente, este concepto de ciudadanía es demasiado restringido para explicar un fenómeno tan complejo. La noción de ciudadanía existe siempre en función de una relación entre sociedad y estado. La palabra ciudadano viene de ciudad; la ciudadanía, desde la polis griega, con su sistema de democracia deliberativa, era una ciudadanía para unos pocos. El concepto de ciudadano que ha primado en los últimos siglos, por lo menos a partir de la Revolución Francesa, se relaciona con el sujeto que tiene derecho a elegir y a ser elegido. Por supuesto que no es el que se discute hoy, sobre todo en los ámbitos educativos, pues resulta inadecuado restringir el concepto de ciudadanía al derecho al voto.

Autores como Parisí y Penna (2009, p. 149), plantean: “Observamos que la ciudadanía no es mera expresión teórica, sino acción concreta, por lo que el ejercicio de ella, está plasmada en la participación política. De no haber participación política, la ciudadanía se constituiría en una entelequia". Esta visión se puede entender como una comprensión restringida al actuar político del sujeto ciudadano, es decir, las acciones más directamente relacionadas con el ejercicio político (el voto durante comicios, militancia en un partido u organización política, manifestaciones públicas sobre el ejercicio de gobierno, entre otras). Hasta cierto punto, esta comprensión estrecha y ha influido en la insuficiente atención que se ha brindado en las instituciones educativas a este importante problema.

Otros autores, como Borón (2002), abordan la "ciudadanía" desde un ángulo más bien jurídico y social, al referirla al reconocimiento mediante el cual una persona tiene derechos y deberes por su pertenencia a una comunidad (en el sentido de un territorio concreto en un momento determinado). Esta posición se enmarca en la tradición liberal de origen latino -dirigida al reconocimiento formal de los derechos jurídicos de la persona ciudadana-, y a la perspectiva comunitaria, de origen griego, orientada al rol del ciudadano como actor social, donde la ciudadanía dependería de esa participación.

De acuerdo con lo expresado, la ciudadanía se concibe como la disposición y preparación del individuo para participar de forma activa y efectiva en la vida social, política y económica de la sociedad en que vive, sobre la base del ejercicio de sus derechos como ciudadano y del cumplimiento de sus deberes, con conocimiento de la organización política y social del país. Además, se considera que la esencia de la verdadera ciudadanía no se asocia solo con el país de origen, un individuo es un verdadero ciudadano cuando se siente parte de una comunidad más amplia, más trascendente: toda la humanidad.

Es bastante común la identificación de la educación ciudadana con la educación cívica. De acuerdo con Caruso (2007) ${ }^{7}$, de la mano de la realidad social y política de los países de la región, se fomentó el desarrollo de una educación cívica cuyos principales componentes eran los contenidos patrióticos: la historia vista desde los hechos heroicos; los símbolos patrios; un conocimiento superficial de las leyes, los derechos y las obligaciones "ciudadanas", etc. Es

7 Caruso Larrainci Arlés, coordinadora del proyecto “Estado de la situación actual de la educación de jóvenes y adultos en América latina y el Caribe", CREFAL-CEAAL / Uruguay. 
URL: http://www.una.ac.cr/educare

CORREO: educare@una.cr

comprensible esta reflexión donde se evidencia que la citada autora discrepe de los conceptos estrechos sobre educación ciudadana.

En una línea similar al pensamiento anterior, Cerutti (2007) subraya que Conde se opone a la idea del "civismo" concentrado en una asignatura, como apuesta para la formación de ciudadanía. Este autor apunta que de esta forma se recupera la definición de educación ciudadana, centrada en las competencias para participar en la toma de decisiones que afectan colectivamente y en privilegiar, por tanto, el aprender a aprender, con toda la carga de reivindicación democrática verdadera.

No es el propósito de este trabajo dilucidar con amplitud las disquisiciones en cuanto a las diferencias y convergencias que puedan existir entre la concepción de educación ciudadana, educación cívica y otros conceptos afines. Existen, como se ha apuntado, puntos de vista muy diversos que dependen fundamentalmente de los enfoques y concepciones que sustentan los estudiosos de este tema.

Muy aparejado a la evocación política, aparece, en relación con la "ciudadanía", el concepto de democracia, que según Montero (1987, p. 19), "como práctica, implicaría la adquisición de derechos y el cumplimiento de una normativa determinada, y la puesta en marcha del ejercicio de la ciudadanía sería entonces la participación en la vida social". De la aportación de este autor se recupera, para este estudio, la significación social de este concepto; pero se discrepa en su identificación con el cumplimiento de derechos y normativas. Si fuera así, ¿dónde queda el aporte de las personas?, ¿cómo sería posible transformar la sociedad?

Del mismo modo, se destaca el nuevo rol docente como modelo, tanto en lo referido a su preparación profesional, como en el sentido de la manera de ofrecer su contribución al desarrollo social, la consolidación de la democracia y el alcance de metas superiores en el desarrollo del ser humano. En lo formativo; el trabajo de la escuela actual aún es pobre y no siempre se corresponde con una realidad compleja, diversa, contradictoria. A ello se suman los efectos derivados de una poderosa influencia, en los estudiantes, de factores como: los medios de comunicación y las tecnologías de la información. Estas insuficiencias implican una separación entre lo que "provee" la institución educativa en materia formativa y la realidad, la vida, donde se concreta su participación como ciudadano o ciudadana.

Ibáñez-Martín (s. f.) precisa determinados aspectos relacionados con la ciudadanía, con el fin de caracterizarla como objeto de investigación, aunque es obvio que, en el proceso formativo, todos los aspectos que la integran se entrelazan y se asimilan como sistema, la separación es producto de una abstracción, útil solo para su análisis y tratamiento pedagógico. De acuerdo con el citado autor, la educación ciudadana posee como esencia la concientización de cada ciudadano sobre el conjunto de derechos y deberes individuales y colectivos (personal, política, civil y social); una actitud solidaria con los demás miembros de la comunidad y la disposición a la participación política activa. 
Se deduce que se trata de educar al estudiantado para el conocimiento y práctica de sus derechos a un nivel de vida digno, recibir los servicios básicos para el bienestar individual y social, participar activamente en las decisiones que afectan su vida particular y social, tanto de la comunidad más inmediata como del país en general. Estos objetivos generalmente no aparecen explícitos en los diferentes perfiles de egreso, por tanto, no reciben tratamiento en las actividades educativas ni son abarcados en la vida interna de las instituciones. Incluso, en ocasiones, se desconoce por docentes y estudiantes la normativa del centro, de la cual -si se habla de derechos ciudadanos- deberían ser partícipes. En este sentido, al analizar los resultados de un estudio, Ávila (2009, p. 69) precisa que los estudiantes "...consideran que, muchas veces, no se da una completa divulgación de la normativa interna, por lo que dicen que urge conocer no sólo los derechos, sino, también, los deberes. Mencionan, además, que cada persona debe apropiarse de la normativa interna".

Una educación ciudadana debe habilitar al estudiantado para actuar adecuadamente como persona y sujeto social, para saber respetar y valorar a los otros y a sí mismo desde una óptica constitucional y humanista, para defender los derechos humanos y preservar el entorno, así como para analizar los aspectos morales de la realidad. Además, para insertarse responsablemente en la sociedad y convertirse en un ciudadano correctamente educado, respetuoso de las normas de convivencia, laborioso, capaz de dar y recibir amor. Asimismo, cumplidor de sus deberes, defensor de los derechos individuales, colectivos y activo participante en la edificación de la sociedad.

Este estudio no comparte las visiones estrechas sobre la educación ciudadana. Por tanto, se identifica, como referente importante, la posición de Landeros (2007) quien expresa que desde un punto de vista limitado, pareciera que la tarea de "formar ciudadanía" desde la escuela se resuelve solo desde un plano académico en el que intervienen contenidos curriculares, métodos y medios de enseñanza. El asunto es más complejo, la formación ciudadana exige a la escuela más que las perspectivas y materiales oficiales; incluso más que los saberes de los maestros. Se trata de un conocimiento, que se toma en cuenta en cada acto educativo, estrechamente vinculado con la vida cotidiana de quienes habitan una nación y el mundo.

A partir de lo analizado, se advierte que las concepciones sobre la educación ciudadana aparecen ineludiblemente ligadas a la participación activa de las personas en el análisis y transformación de la realidad, incluso más allá de ella, pero es a través de una verdadera democracia como es posible concretar ese "deber ser ciudadano".

Las ideas que en este estudio se preconizan son opuestas a la comprensión del cumplimiento de deberes y derechos como un dogma, así como al aprendizaje memorístico de unas normas de conducta, y de otros aspectos que atañen a la ciudadanía. Se trata de una participación ciudadana activa, basada en una madurez personal que se complemente con las exigencias de su comunidad y la sociedad en general, en función de un bien común. De aquí surge una relación que ha de ser abordada en la práctica de la educación ciudadana democrática: la que se establece entre el mundo en general, y cada país, comunidad, escuela, grupo, etc. 
URL: http://www.una.ac.cr/educare

CORREO: educare@una.cr

De acuerdo con el análisis de las fuentes que abordan la educación ciudadana, fue posible encontrar algunas regularidades en las interpretaciones y enfoques, entre las que se encuentran:

- Se consigna como parte de la formación integral del individuo, al comprender el actuar activo como ciudadano, en cada contexto de actuación.

- Se identifica con la educación cívica, como asignatura.

- Se asume como una asignatura en sí misma.

- Se trabaja como un eje transversal del currículo.

- Se prepondera su aplicación especialmente en la política, los aspectos jurídicos, entre otros.

- Solo en las últimas décadas se identifica la necesidad de trabajar la educación ciudadana desde las instituciones escolares.

El reconocimiento de las posiciones anteriores justifica cualquier esfuerzo por mejorar la preparación del estudiante para un desempeño efectivo en la sociedad, que a su vez resulte satisfactorio para él como persona. Cuando este hecho ocurre como resultado de una presión externa, no revierte valor ni social ni personal, precisamente porque puede dejar de manifestarse, al momento de no sentir la presión. De otra forma, no existirá, entonces, una formación verdadera, consciente, sino simplemente un formalismo, un adoctrinamiento. Por ello, resulta indispensable, también, el reconocimiento de la educación ciudadana en el crecimiento personal. Por tanto, la educación ciudadana no se ha de dejarse solamente a lo que pueda hacer la escuela, la familia, la influencia educativa del medio y la de aislados ejemplos; o a lo que puede hacer la "transmisión" de tradiciones populares, sino que debe proyectarse el trabajo de forma consciente y coherente, sobre la base de las teorías, como generalizaciones de buenas prácticas educativas en correspondencia con el tipo de institución.

Con frecuencia se piensa que la formación ciudadana puede tener buenos resultados, si se integran asignaturas en el currículo con este objetivo; sin embargo, como apuntan García y Flores (2011), existen datos que no corroboran esta idea acerca de los efectos del currículo en la formación estudiantil. Los resultados arrojados por los estudios de (Shulz, Ainley, Fraillon, Kerr, y Losito, 2010; Torney-Purta, Lehmann, Oswald, Shulz, 2001) al comparar los datos arrojados por investigaciones realizadas con grupos de alumnos educados a partir de distintos programas de formación ciudadana, manifiestan que no existen variaciones en relación con el conocimiento y las actitudes ciudadanas, pese a que los estudiantes componentes de la muestra en el año 2009 fueron formados con el nuevo currículo. Esto constituye una clara evidencia de que, pese a las transformaciones curriculares, no se ha logrado formar a los ciudadanos y ciudadanas que una sociedad democrática necesita. 
De allí que la visión acerca de que la educación ciudadana ha de ser parte consustancial de toda actividad en la institución educativa y no de una disciplina en particular. Esta formación, para que sea verdaderamente autotransformadora del estudiantado y a su vez transformadora de la realidad, ha de develarse mediante una participación activa y consciente del estudiantado, en cada una de las decisiones personales, escolares, familiares, etc.

\section{Concepciones sociopedagógicas sobre ciudadanía y democracia}

Los conceptos de ciudadanía y democracia son conceptos dinámicos, pero poseen historicidad y se renuevan con las transformaciones sociales. Etimológicamente, desde su origen en la Grecia clásica, democracia significa poder del pueblo, que era entendido como ciudadanía. Para los griegos, la ciudadanía era sinónimo de igualdad donde todos los miembros de la sociedad gozaban de iguales derechos para participar en la toma de decisiones políticas. A partir de los aportes de los filósofos ilustrados, a la idea de democracia se le añadió el concepto de soberanía, comprendida como el poder de gobernar, dicho poder se encontraba en la nación, en los ciudadanos, quienes debían depositar la cuota de poder que les correspondía en representantes del gobierno. Surge así el concepto de democracia representativa y el de ciudadano pasivo, depositario de la soberanía. Actualmente, tras los cambios políticos y económicos que se suceden vertiginosamente desde comienzos del siglo XX, tanto la idea de democracia como la de ciudadanía han presentado transformaciones significativas, sobre todo en el discurso, pues en la práctica todavía no satisfacen las necesidades ni personales ni sociales.

En el pensamiento griego es donde inicia la interdependencia entre democracia y educación, ya que la educación estaba presente en la vida misma y esta representaba la escuela de la ciudadanía. En la antigua Grecia, para cuya sociedad los valores eran de suma importancia, se asumían como principales: la democracia, la libertad, la belleza y la verdad.

El concepto de "formación ciudadana", por su parte, indica como meta formativa, hacia los estudiantes, el logro de personas con clara conciencia de sus derechos, deberes y de la importancia de su participación en la dinámica del contexto social y político. La formación ciudadana es aquel potencial del individuo capaz de argumentar sus demandas, sus intereses y necesidades sociales, a la vez capaz de entender el razonamiento de los demás, el planteamiento de los otros, la diferencia y la disidencia (Savater, 2009).

Ser ciudadano significa poseer valores, actitudes y comportamientos democráticos: libertad, pluralidad, respeto, participación, identidad, y crítica argumentada, actividad transformadora y la sensibilidad que demanda el momento y contexto histórico y social. Desde este enfoque, el propósito de la formación ciudadana en las instituciones educativas va más allá de la simple institución del conjunto de normas que regulan la vida social y la formación de valores, para ubicarse en la aplicación y comprensión de los saberes y actitudes que permiten al estudiante integrarse a la sociedad y participar de la reconstrucción de la dimensión pública, del ámbito de la democracia y de los valores éticos y políticos que conforman la sociedad y su ordenamiento. 
URL: http://www.una.ac.cr/educare

CORREO: educare@una.cr

Estos procesos deben iniciarse en la familia, especialmente desde la edad escolar y en todos los niveles de las instituciones educativas. Como afirma Uribe (1995): Pensando el mundo de la escuela como partícipe de ese mundo público, que es el encuentro del niño o del joven con una colectividad compleja, en la cual es un sujeto individual, particular, el cual se encuentra con otros sujetos particulares e individuales que no están unidos a él por ningún lazo afectivo, parental, doméstico o natural.

Según la citada autora (Uribe, 1995), debe ser la escuela el espacio fundamental para la formación ciudadana, por varias razones: es el lugar donde se da el primer encuentro con las diferencias $y$, en esa medida, con el autoconocimiento; es una organización formal regida por normas y con objetivos determinados, en ella se encuentra la ley que implica unas normas, unas obligaciones y unos derechos; el principio de orden y de organización social donde se socializan las formas de racionalidad.

Por las razones apuntadas, se ha de partir de un concepto de ciudadanía que comprenda "con realismo las exigencias mínimas de lo que debe ser un ciudadano democrático, . . . sin convertirle en un concepto vacío" (Del Águila, p. 40). La educación ciudadana apunta a la inserción creativa y dinámica del estudiantado dentro de una sociedad democrática, que le permita un mayor desarrollo de sí mismo y de la sociedad en la que vive.

De esta forma, se considera ciudadano o ciudadana, a aquella persona que es participativa desde su juicio político (entendido este como la combinación de sentido moral y justicia) frente a lo intolerable y diferente, con capacidad reflexiva y crítica. Esta participación se apuntala desde lo que Magendzo (2003) denomina un sujeto de derecho, pues es capaz de hacer uso de su libertad, al aceptar los límites de esta; de reivindicar el ideal de la igualdad, reconociendo la diversidad, y de valorar la solidaridad desarrollando una actitud de respeto mutuo; es decir, de aceptación de la otra persona como un legítimo otro, como un ser diferente, autónomo en su capacidad para actuar y exigir que otros tengan una actitud semejante con él. Estos principios pueden encontrar su concreción en cada contexto y esfera de actuación del estudiantado; en sus relaciones con sus compañeros y compañeras, docentes, directivas, en su ámbito familiar y comunitario; pero si en las instituciones educativas no reciben un adecuado tratamiento, lógicamente no se traduirá en comportamientos acordes con dichos principios.

La formación ciudadana ha de permitir a los estudiantes y a las estudiantes la participación de manera decidida, consciente y autónoma en la defensa de los derechos para el bien de su colectivo. Según Ospina (2000): "Para que la formación ciudadana sea una realidad es necesario también reeducar al maestro. Porque él tampoco creció con los referentes de justicia, participación democracia y respeto. El profesor es fruto de la historia de este país legada por la falta de participación, la intolerancia y el irrespeto por la diferencia" (p. 5). La formación del ciudadano desde la institución educativa debe estar destinada no solo a consolidar la democracia como lo hace el régimen político, sino a potenciar el desarrollo de la democracia como un estilo de vida que favorece la convivencia. Educar para la democracia representa aprender a vivir en democracia, manifiestar la capacidad de actuar cívica y responsablemente, evidenciando valores 
como la justicia, la libertad, la responsabilidad, la legalidad, el pluralismo, la tolerancia, el respeto mutuo, la participación y la democracia propiamente dicha. La formación ciudadana de las jóvenes generaciones constituye una necesidad debido a su repercusión que en la vida social y personal. La asunción responsable de los deberes que se asimilan desde el tiempo de estudios posibilita el valer los derechos tanto en ese período como en su vida futura.

A partir del análisis realizado, la educación ciudadana, en este trabajo, se define como el proceso constate de preparación del estudiantado en cuanto a la adquisición de los conocimientos, habilidades y valores para participar de manera activa y transformadora en los diferentes ámbitos: personales, escolares, comunitarios, del país y de la humanidad en general.

El análisis de las fuentes que aportan diferentes criterios y perspectivas de la educación ciudadana, así como la experiencia de los autores en el ámbito educativo, facilitan la determinación de los componentes fundamentales que integran la educación ciudadana. Para este estudio se consideran como indispensables los siguientes:

- La identificación, conocimiento y cumplimiento de los deberes y derechos de los ciudadanos (escolares, espirituales, familiares, sociales, etc.)

- Asunción de responsabilidades personales y colectivas

- Preparación para una participación efectiva en actividades de diversa índole (patriótica, social, política, cultural)

- Actuación democrática del estudiantado, como comprensión y a la vez como instrumento para la inserción activa, en la solución de los problemas en los diferentes contextos, mediante un equilibrado y adecuado vínculo de lo personal y lo social.

El tema de la democracia no siempre aparece asociado al de ciudadanía. Ha sido objeto de estudio de la filosofía, la sociología, incluso de la dirección científica (referente a los estilos de dirección), entre otras disciplinas. Sin embargo, desde la teoría y la práctica pedagógica, ha sido tratada insuficientemente. Posiblemente en muchas sociedades se ha omitido en las políticas educativas, con conocimiento de causa-efecto y, en otras, se ha cedido su tratamiento a otras instituciones, organismos, organizaciones e instituciones con exclusión de la escuela en sus diferentes niveles. Incluso, con frecuencia se identifica la democracia solo como un problema político.

Comúnmente, cuando se hace referencia al concepto democracia, se piensa en los valores que encierra dicho concepto, de aquí su amplitud y sus múltiples interpretaciones. La cuestión radica no solo en determinar estos valores, sino de qué forma pueden consolidarse en las instituciones educativas a través de estrategias concretas para la consecución de una verdadera cultura democrática. Entre estos valores destacan: la libertad, la justicia, la participación, 
URL: http://www.una.ac.cr/educare

CORREO: educare@una.cr

la pluralidad, el respeto mutuo, la tolerancia, la solidaridad y la comunicación. Reconocer determinados valores contribuyen a educar para la democracia, por tanto, se concuerda con esta posición, considerando que son rasgos esenciales de la democracia, lo que no significa entenderla como la suma de dichos conceptos.

Desde una perspectiva similar, Sen (2002) explica que la democracia involucra exigencias complejas, que incluyen el voto y el respeto hacia los resultados; pero también implica la protección de las libertades, el respeto a los derechos legales y la garantía de la libre expresión y distribución de información y crítica. La práctica de la democracia, según este autor, ofrece a la ciudadanía la oportunidad de que unas personas aprendan de otras y ayuda a la sociedad a formar sus valores y prioridades, cuestiones esenciales a considerar en cualquier nivel educativo.

\section{La democracia como cualidad esencial de la educación ciudadana}

Lo anterior comunica la idea de otorgarle una gran significación a la democracia cuando se enfatiza en su decisiva importancia para la construcción colectiva de una nueva sociedad. Incluso con frecuencia se usa el término "educación ciudadana democrática"8. Quiere decir que la democracia le impregna un rasgo característico al quehacer ciudadano. Por esta razón, no es discordante, según postula este estudio, el empleo de este término.

La democracia como cualidad esencial de la educación ciudadana también es educable, de ahí que diferentes autores hagan referencia a ella como un aspecto a superar en las instituciones educativas. Así, Smith (2001) afirma que, si en las escuelas se pretende promover valores democráticos, se necesita eliminar las relaciones autoritarias.

Existen varios trabajos que otorgan un alto valor a la "educación para la democracia", término acuñado hace varios años y que ha cobrado vigencia en la actualidad. Entre otros autores que abordan la democracia desde una óptica educativa y pedagógica, destacan: García, (2011); Guevara (1998); Hoyos (1995); Leiva (1999); Oneto (2007); Prieto (2001) y Toro (2007).

Al considerar que la escuela ha de ser un reflejo de la sociedad ideal, es importante tener en cuenta estos elementos en el tratamiento pedagógico de la democracia, pues cuando el estudiante se prepara en el sentido planteado por Sen (2002), entonces, podrá contribuir con el funcionamiento de la sociedad, de acuerdo con dichas expectativas. Es obvio que la democracia no solo significa poder del pueblo, expresión tan confusa que se puede interpretar en todos los sentidos, hasta para legitimar regímenes autoritarios y represivos; puesto que es muy común en esos regímenes que las decisiones descienden del estado hacia el sistema político, luego hacia la sociedad civil. En este proceso se da participación a los ciudadanos, no tanto para tomar en cuenta sus propuestas, sino para aparentar que existe una amplia participación ciudadana.

8 Varios ponentes del Seminario "De la identidad local a la ciudadanía universal: el gran reto de la educación contemporánea", hicieron alusión a este tipo de educación y usaron este término. 
De acuerdo con una visión más abarcadora, la democracia es una “. . . forma de vida que tiene implicaciones y manifestaciones en la vida cotidiana. Por lo tanto, tiene que estar profundamente arraigada en los patrones culturales que se producen y reproducen en [el quehacer diario], en la familia, en la escuela, en el trabajo, en los medios de difusión y todos los lugares de las esferas pública y privada" (Sánchez, 2004, p. 2). Esta idea reafirma el papel de la escuela en la educación desde la democracia y para esta, por lo que constituye un referente importante en el presente trabajo.

Por otra parte, según Toro (2007), la democracia no se puede identificar como un partido, una religión o una ciencia, sino que es una forma de ver el mundo: una cosmovisión. Vista de esa manera, tiene la particularidad de que conservándolo todo, lo ordena de manera diferente. Desde esta perspectiva, este autor introduce el concepto de ethos democrático, que consiste formas democráticas de pensar, sentir y actuar, y puntualiza los siguientes principios, para la comprensión de la democracia y su implicación para el proceso formativo del estudiantado:

1. Principio de secularidad: todo orden social es construido. El orden social no es natural, por eso son posibles las transformaciones de la sociedad. La democracia no es natural al ser humano, por ello es necesario enseñarla y aprenderla.

2. Principio de incertidumbre: no existe un modelo ideal de democracia que se pueda copiar o imitar, cada sociedad debe crear su propio orden democrático. A cada sociedad le corresponde comenzar a construir el orden democrático a partir de su historia, sus conocimientos, su tradición, su memoria; a partir de lo que es y lo que no es, de lo que tiene y de las proyecciones que puede hacer.

3. Principio ético: aunque no existe un modelo ideal de democracia, todo orden democrático está orientado a hacer posibles los derechos humanos, a cuidar y proteger la vida, a trabajar por el bien común.

4. Principio de complejidad: el conflicto, la diversidad y la diferencia son constitutivos de la convivencia democrática. Una sociedad comienza a resolver sus conflictos y a adquirir una conducta democrática cuando asume el concepto necesario de oposición, y aprende a deliberar y converger.

En las fuentes referenciadas se observa una gama de términos y enfoques de la democracia en el campo educativo. Entre los más difundidos están su definición como cosmovisión, forma de vida, como un valor en sí misma, como valor que integra un conjunto de valores. Los términos más usados asociados con su educación son: educación democrática, educación para la democracia y educación en la democracia. En este caso, se concibe asociada a la educación ciudadana y afiliada, esencialmente, a la libertad de expresión, la igualdad, el respeto y la implicación personal consciente en unidad con los intereses sociales. De aquí que los términos 
URL: http://www.una.ac.cr/educare

CORREO: educare@una.cr

"educación para una ciudadanía democrática" o "educación ciudadana democrática" hacen notar que la democracia se instituye como su rasgo esencial.

La democracia es el rasgo esencial de la educación ciudadana, ya que la percepción del estudiantado de su propia ciudadanía y la participación comunitaria son imposibles de alcanzar sin una participación activa y abierta en todas aquellas decisiones y procesos relacionados con sus vidas. Por esta razón, los diferentes enfoques pedagógicos hacia la formación tienen un impacto significativo para la asimilación de los valores y la conciencia ciudadana.

La necesidad de fortalecer la democracia desde la escuela está latente en todos los países del mundo. En este sentido, Carr (2008) destaca que "... si bien muchos factores participan de la formulación y encuadre de la democracia en las escuelas, los profesores juegan un rol muy claro e importante a la hora de cultivar y moldear la experiencia educativa de los estudiantes en relación con sus actitudes, conductas, ideologías y compromisos - presentes y futuros - en torno a la democracia" ( p. 149). Es frecuente que en las instituciones educativas se mantenga la tendencia hace mucho obsoleta de considerar al estudiante como objeto de formación, pero es precisamente porque tanto para directivos como para educadores la práctica de la democracia no constituye un objetivo primordial del trabajo educativo.

Se podría justificar que el tan esgrimido "protagonismo estudiantil", la posición de sujeto del estudiantado y los métodos participativos, entre otros, podrían sustituir la esencia de esta práctica milenaria; empero, no es tan simple el asunto. Precisamente por estar ausente como contenido, forma y método en las instituciones educativas, con frecuencia, los estudiantes son objeto de abusos de todo tipo por docentes, directivos, y más bien se acogen a la "práctica del silencio" para evitar ser objeto de represalias. Lógicamente, en tales casos, confluyen diversos aspectos y factores, pero sin lugar a dudas una práctica educativa transparente, participativa, a fin de cuentas democrática, podría contribuir en mayor medida a la formación del hombre que necesita la sociedad de hoy.

La posibilidad de pensar y actuar por sí mismos como elementos claves de la democracia se podría alcanzar mediante la educación, en conjunto con las múltiples instituciones educativas y culturales existentes. Sin embargo, la educación autoritaria y represiva no acaba de ceder al paso a una de tipo diversa, plural, reflexiva, potenciadora del criterio propio. Cuánta razón tenía Enrique José Varona9 cuando expresó: "¿Quién me tiraniza?, ¿el que me sofoca, me descoyunta, me azota, me atenaza o me tuesta a fuego lento? No. El que me obliga a ocultar o simular lo que pienso" (Varona, 1981, p. 76).

No obstante, en los últimos años se ha revalorizado el tema de la democracia en los diferentes ámbitos educativos. Autores como Tiana (2008) hacen referencia a la idea de trabajar el tema de la ciudadanía democrática. Una muestra de esta preocupación es la inclusión, entre los objetivos europeos para 2010, uno que dice textualmente: "Velar porque entre la comunidad

9 Varona, Enrique José fue un insigne pedagogo cubano que realizó grandes aportes a la práctica educativa, en sus escritos subyace una esencia profundamente democrática y que mantiene una gran vigencia y actualidad. 
escolar se promueva realmente el aprendizaje de los valores democráticos y de la participación democrática con el fin de preparar a los individuos para la ciudanía activa"10.

Para Pereira (1997), la democracia es un valor afectivo-social en el que el ser humano:

- Tiene conciencia de sus derechos y deberes como persona, y está preparado y dispuesto a colaborar en el desarrollo, defensa y apoyo de la democracia que busca promover los valores personales y comunitarios del país.

- Tiene la capacidad para denunciar cualquier tipo de desorden.

- Trabaja para propiciar el establecimiento de un buen gobierno en cualquier institución y nivel.

- Tiene capacidad crítica y libertad para expresarse.

- Se relaciona positivamente con los demás.

- Otorga importancia a las normas de convivencia familiar y social.

Aunque se concuerda en lo esencial con lo expresado anteriormente en cuanto a la concepción de la democracia como valor, por el contenido atribuido, según la orientación que guía esta investigación, se concibe como una cualidad de la educación ciudadana que se enfoca mas bien desde una <pluralidad de valores> que comprenden, en primer lugar, la importancia intrínseca de la participación, la libertad individual y social para la vida humana.

\section{Consideraciones sobre el abordaje pedagógico de la democracia}

El tratamiento pedagógico de la democracia ha sido poco estudiado, puede concebirse como la inclusión de todos los sujetos y factores que influyen en el proceso formativo del estudiante desde todos los componentes del proceso educativo hasta las múltiples relaciones que pueden establecerse en la escuela, y entre ella y la familia, los diferentes agentes de la comunidad, así como los factores de influencia del país y del mundo en general. Una pedagogía centrada en la democracia ha de abrirse a la comunidad, al país, al mundo. Este proceso discurre a partir de una identidad subjetiva y en relación con los otros (maestros, estudiantes, directivos, otro personal, los agentes de la comunidad, la familia). En el caso de la escuela, de tal manera que se vaya construyendo un nosotros colectivo, en donde es el diálogo y la convivencia los que permiten esa relación.

10 Estos objetivos fueron formulados en el contexto de la denominada "Estrategia de Lisboa". 
URL: http://www.una.ac.cr/educare

CORREO: educare@una.cr

Relacionado con el abordaje pedagógico de la democracia, es común que aparezca en la bibliografía el término "educación para la democracia". Lógicamente ello requiere de una legitimación de los procesos que en ella se viven, de validar los significados de los actos y prácticas, convocando a estudiantes, profesores y administrativos a participar de manera solidaria y colaborativa en esta tarea.

El plan de estudios puede incluir, en su contenido, la importancia de tratar a todas las personas con respeto y dignidad. Sin embargo, el currículo oculto trasmite un mensaje totalmente diferente, por ejemplo, cuando los comportamientos agresivos y la intimidación se toleran, o cuando se muestran discriminación a los escolares de barrios marginales o que presentan problemas sociales. Por ello, diferentes autores hacen referencia al sistema ideológico que ella inspira. Según Bueno (2007) consiste en los principios de:

1. Humanismo laico: intenta ver al ser humano desde el hombre, quien es la medida de todas las cosas.

2. Humanismo ético: atribuye a los sujetos humanos individuales la condición de entidades supremas, libres, fuentes de todos los derechos y valores.

3. De la cooperación: establecida mediante el diálogo respetuoso, tolerante, no violento y compresivo del otro.

4. Armonía preestablecida: la que ha de lograrse a través del diálogo y alianza de las civilizaciones y países.

Las instituciones educativas escolares y extraescolares no pueden ser un espacio donde todo esté preestablecido, donde se obstruya la actividad de los estudiantes y se impida que se expresen y exijan sus derechos; por el contrario, ha de respetar el equilibrio entre obligaciones y demandas. Cuando los estudiantes y las estudiantes se desestiman, no se tienen en cuenta sus inquietudes y propuestas, entonces, lo impuesto les será ajeno, extraño y la mayoría de las veces indiferente. En consecuencia, para que las instituciones educativas sean democráticas, se requiere, entre otros aspectos: fomentar la participación de todos sus miembros, a partir de la deliberación colectiva y del debate racional, que permitirá tomar posición ante la realidad de acuerdo con su idiosincrasia, pensando y actuando autónomamente para resolver problemas (Prieto, 2001).

Debe entenderse que el abordaje pedagógico de la democracia parte de la esencia misma de la escuela en su función socializadora. No se trata solamente de seleccionar o elaborar métodos o procedimientos que ayuden a educar en la democracia, sino también de la creación de un clima y estilo de trabajo que propicie el logro de este objetivo. En diferentes países, como por ejemplo México, la formación en la democracia es objeto de la asignatura educación cívica, incluida en 
el currículo a partir del ciclo escolar 2008-2009. El Programa Sectorial de Educación (2007) de la Secretaría de Educación Pública 2007-2012 de México (SEP) destaca como objetivo esencial: "realizar actividades y talleres con el fin de que los estudiantes tengan una clara conciencia de sus derechos y obligaciones como ciudadanos, y de promover la participación ciudadana" (p. 44).

Desde la perspectiva de este estudio, no se asume una posición contraria a la existencia de una asignatura, como la educación cívica, dirigida especialmente a la educación ciudadana y, por tanto, también a la democracia; pero se subraya la idea de que la educación para la democracia va mucho más allá del estudio de una asignatura, pues incluye toda la actividad del alumnado y de la institución educativa. Al respecto, Gutiérrez (2008) considera que para educar en la democracia es importante la plena participación del alumnado, situación que le permitirá actuar como persona libre y responsable y adquirir actitudes que le impulsarán a enfrentarse crítica, consciente y positivamente con los problemas propios de la vida en grupo. Agrega que la escuela debe autodeterminar la responsabilidad, pues es ahí donde es posible vivenciar el pluralismo de ideas en un clima de libertad, haciendo hincapié en una educación autogestionaria que comprenda la participación, la comunicación, la creatividad y el compromiso individual y social.

Desde una perspectiva similar, educar en la democracia requiere de la indagación crítica, respeto por la libertad de las personas, la justicia social y el diálogo (Giroux, 1993). En correspondencia con el criterio de este autor y aunque parezca insólito, en muchos centros educativos, hoy día, se mantiene un estilo de comunicación autocrático tanto por profesores como por los directivos: la educación para la democracia empieza por el respeto al orden, la disciplina, a las demás personas; pero tiene su esencia en la plena independencia de los individuos.

Es obvio que el tratamiento pedagógico de la democracia implica tener en cuenta que esta se enseña y se aprende, se refleja en la actuación consciente del personal docente y directivo, y del estudiantado, a partir del funcionamiento de la institución educativa. Responde a las exigencias sociales e involucra a todos los actores de la educación, dentro y fuera de la escuela, y exige ineludiblemente la proyección coherente del proceso pedagógico, lo cual indica una adecuada coherencia entre el ser y el deber ser.

De acuerdo con Santos (citado por Prieto, 2001), la práctica democrática en la escuela se basa en el diálogo permanente, el debate abierto y la crítica efectiva; así logra que los alumnos y alumnas sean agentes de su propia educación y adquieran responsabilidades en el proyecto escolar, comunitario y del país. Como se observa, las ideas sobre la educación para la democracia desde los centros educativos convergen en muchos aspectos. De esta forma, con la concepción de Leiva (1999), la democracia en la escuela debe enseñarse mediante la participación, el diálogo, la libertad de expresión, el debate de ideas y el trabajo comunitario, situaciones que permitirán al alumnado compartir el control sobre la experiencia y ser escuchado sin reproches ni sanciones.

Un adecuado enfoque pedagógico de la democracia revela la necesidad de dar tratamiento a su educación desde la comprensión de las leyes pedagógicas, esencialmente 
URL: http://www.una.ac.cr/educare

CORREO: educare@una.cr

la relacionada con el vínculo de la escuela con la vida, priorizando la participación activa y consciente del estudiante, teniendo en cuenta las particularidades del proceso educativo, en especial su carácter bilateral y activo. No obstante, se postula que el término democracia no se debe enmascarar con otros términos, por cuanto posee una gran connotación en la vida socio-política de cualquier país. Por tanto, se requiere un tratamiento directo y consciente a su concreción.

El tratamiento pedagógico a la democracia requeriría entre otras cuestiones de:

\section{Potenciar la independencia de los estudiantes}

Existe una insuficiente comprensión acerca de que la escuela no es para adoctrinar, ni siquiera para inculcar ideas, sino para desarrollar en el estudiantado sus propias ideas. Tradicionalmente se ha relegado la formación creativa, independiente, olvidándose de que el alumnado está compuesto por seres creativos, por lo que ha de potenciarse la expansión de la consciencia y autonomía individual.

\section{Fomentar la necesidad en los estudiantes de argumentar criterios propios}

Se habla bastante de la discriminación de razas, etnias, nacionalidades, sexos, preferencias sexuales, de credo; sin embargo, se trata poco o casi nada la discriminación por las ideas propias o diferentes. En las escuelas al personal docente le sigue satisfaciendo que sus estudiantes hagan todo lo que les indican, sin ningún tipo de oposición y objeción, quieren que les crean sin refutar, sin disentir, que contesten como "les han enseñado".

Aplicar métodos de enseñanza y aprendizaje que permitan estimular los intereses de alumnos y docentes para guiar el desarrollo

La zona de desarrollo potencial induce precisamente a esto, a que el aprendizaje conduzca al desarrollo. Frecuentemente se habla de tomar en cuenta motivos e intereses del estudiantado; pero, ¿y si no existieran? Por ejemplo: ¿muchos estudiantes y docentes demandan, como ámbitos competenciales, el conocimiento histórico o el deber de memoria, la madurez personal, la autoconciencia sincrónica o histórica, el autoconocimiento, la complejidad de conciencia o la superación del propio egocentrismo individual y colectivo? Aunque estos constituyen aprendizajes imprescindibles para la formación de las personas, no toda necesidad fundamental se demanda, bien porque no se haya concientizado su importancia o porque no interese en primer plano a los sistemas que la perciben y que generalmente utilizan la escuela para consolidar sus intereses. Por ello, le corresponde a la escuela proyectar su trabajo en función de lo que la sociedad realmente necesita, que no siempre se corresponde con las demandas de los gobiernos, aún de aquellos que se hacen llamar democráticos. 


\section{Conclusiones}

Para la participación activa en la vida social, los estudiantes y las estudiantes deben desarrollar un conjunto de capacidades, habilidades y actitudes que les conduzcan a la adhesión autónoma y racional de aquellos elementos que orientan la convivencia social, asimismo que les permitan aportar a la transformación de aquellos procesos que constituyen la esencia de la vida en común.

El análisis de las fuentes de las diferentes disciplinas relacionadas con el tema de la ciudadanía y la educación ciudadana permite corroborar la necesidad de continuar en la búsqueda de posiciones teórico metodológicas que, aunque desde ángulos diferentes, converjan en cuanto a las cuestiones esenciales para su abordaje sociopedagógico. Las múltiples interpretaciones, a veces inadecuadas acerca de su contenido y significado, pueden constituir una entropía para el establecimiento de vías para su concreción en la práctica educativa. Es frecuente encontrar criterios inadecuados en los centros educativos, acerca de la educación de la democracia, por cuanto se le considera un aspecto eminentemente político que atañe a otras instituciones sociales.

La educación ciudadana del estudiantado ostenta, como su cualidad esencial, la democracia, la cual desde la perspectiva de este estudio se ubica en un lugar preferente para la inclusión activa y consciente del estudiantado en su autotransformación, en su institución y en su comunidad con sentido de ciudadano o ciudadana universal. La educabilidad de la democracia constituye una necesidad social que debe ser abordada, atendida y afrontada desde las instituciones educativas, pues los actores del contexto educativo se encuentran entre los principales agentes para el cambio social. Autores que abordan la problemática de la educación ciudadana democrática desde las instituciones educativas reconocen la importancia de que desde puestos directivos y docentes tracen estrategias concretas orientadas a este fin.

\section{Referencias}

Ávila, F. (diciembre, 2009). El desarrollo de foros estudiantiles como estrategia para fortalecer la enseñanza de la cívica. La experiencia del Primer Foro Regional de Gobiernos Estudiantiles. Revista Electrónica Educare, 13(2), 63-73. Recuperado de http://www.revistas.una.ac.cr/ index.php/EDUCARE/article/view/1492

Baeza-Correa, J. (2013). "Ellos" y "nosotros": La (des)confianza de los jóvenes en Chile. Revista Latinoamericana de Ciencias Sociales, Niñez y Juventud, 11(1), 273-286. doi: 10.11600/1692715x.11118140512

Borón, A. (2002). Desarrollos de la teoría política contemporánea. Rosario: Homo Sapiens.

Bueno, G (abril, 2007). Sobre la educación para la ciudadanía democrática. El catoblepas, 62. Recuperado de http://www.nodulo.org/ec/2007/n062p02.htm

Carr, P. (junio, 2008). Educadores y educación para la democracia: Trascendiendo una democracia "delgada". RIED IJED, 1(2), 146-166. Recuperado de http://www.dhl.hegoa.ehu.es/ ficheros/0000/0537/Educadore...pdf 
URL: http://www.una.ac.cr/educare

CORREO: educare@una.cr

Caruso, A. (mayo-agosto, 2007). Reflexiones acerca de la educación ciudadana: Una mirada desde América Latina. Decisio. Saberes para la acción en educación de adultos, 17, 3-8. Recuperado de http://tumbi.crefal.edu.mx/decisio/images/pdf/decisio 17/decisio17 saber1.pdf

Cerutti, H. (2007). ¿Educación para una ciudadanía responsable y participativa? [Reseña]. Perfiles educativos, 29(116), 143-148. Recuperado de http://www.scielo.org.mx/pdf/peredu/ v29n116/v29n116a9.pdf

Comisión Económica para América Latina y el Caribe (CEPAL). (2007). Cohesión social: Inclusión y sentido de pertenencia en América Latina y el Caribe. Santiago, Chile: Autor. Recuperado de http://www.eclac.org/publicaciones/xml/4/27814/2007-382-Cohesion social-REV1-web. pdf

Conde, S. (mayo-agosto, 2007). La educación ciudadana centrada en el desarrollo de competencias cívicas y éticas. Decisio. Saberes para la acción en educación de adultos, 17, 21-25. Recuperado de http://tumbi.crefal.edu.mx/decisio/images/pdf/decisio 17/decisio17 saber4.pdf

Del Águila, R. (1996). La participación política como generadora de educación cívica y gobernabilidad. Revista Iberoamericana de Educación, 12, 31-44. Recuperado de http:// www.rieoei.org/oeivirt/rie12a02.pdf

García, C. y Flores, L. (2011). Los desafíos de la formación ciudadana y la cohesión social frente a la des-subjetivación del sistema. Hacia una interpretación del fenómeno social desde la subjetividad. Estudios Pedagógicos, 37(2), 329-344.

García, T. (2011). Rompiendo muros. La educación democrática: Proyecto comunal de ciudadanía. Revista Electrónica Interuniversitaria de Formación del Profesorado, 14(2), 57-69. Recuperado de http://www.aufop.com/aufop/uploaded_files/articulos/1311954456.pdf

Giroux. H. A. (1993). La escuela y la lucha por la ciudadanía. Pedagogía crítica de la época moderna (3a ed.). México, DF: Siglo XXI.

Guevara, G. (1998). Democracia y educación. México: Instituto Federal Electoral.

Gutiérrez, F. (2008). Educación como praxis política. México: Siglo XXI.

Hoyos, G. (enero-abril, 1995). Ética comunicativa y educación para la democracia. Revista Iberoamericana de Educación, 7, 65-91. Recuperado de https://docs.google.com/ gview?url=http://gilbertobonilla.files.wordpress.com/2009/07/etica-comunicativa-yeducacion-para-la-democracia-guillermo-hoyos.pdf\&chrome=true

Ibáñez-Martín, J. A. (s. f). Educar para una ciudadanía solidaria. ПAILEIA Recuperado de http:// www.bu.edu/wcp/Papers/Educ/Educlban.htm

Landeros, L. (mayo-agosto, 2007). La trayectoria ciudadana y su papel en las concepciones docentes sobre la formación cívica y ética: Algunos hallazgos. Decisio. Saberes para la acción en educación de adultos, 17, 51-56. Recuperado de http://tumbi.crefal.edu.mx/ decisio/images/pdf/decisio 17/decisio17 saber10.pdf 
Leiva, P. I. (1999). Educación para la democracia: Recuento de experiencias internacionales. Estudios Pedagógicos, 25, 91-112. Recuperado de http://www.scielo.cl/scielo.php?pid=S0718$\underline{07051999000100006 \& \text { script }=\text { sci arttext }}$

Magendzo, A. (2003). Currículo oficial y la cotidianidad de la escuela, una lectura desde la investigación. Bogotá: Ministerio de Educación.

Montero, M. (1987). A través del espejo: Una aproximación teórica al estudio de la conciencia social en América Latina. En M. Montero (Coord.), Psicología política latinoamericana (pp. 163-202). Caracas: Panapo.

Oneto, F. L. (2007). Educación en valores democráticos: La historicidad de la democracia como apertura de las narraciones. Revista Interamericana de Educación para la Democracia, 1(1), 87-96. Recuperado de https://scholarworks.iu.edu/journals/index.php/ried/article/ viewFile/114/211

Ospina, E. (2000). Formación ciudadana (Tesis de maestría). Universidad de Antioquia, Medellín.

Parisi, E. y Penna, F. (2009). Mecanismos formales y resolución de conflictos en escuelas de la ciudad de San Luis, Argentina. Revista Electrónica de Psicología Política, 7(21), 147-156. Recuperado de http://www.psicopol.unsl.edu.ar/diciembre 2009 Nota10.pdf

Pereira, M. N. (1997). Educación en valores. Metodología e innovación educativa (4ª reimpresión). México: Trillas.

Prieto, M. (2001). Educación para la democracia en las escuelas: Un desafío pendiente. Revista Iberoamericana de Educación (OEI). Recuperado de http://www.rieoei.org/ deloslectores/497Prieto.pdf

Programa Sectorial de Educación. (2007). Secretaría de Educación Pública 2007-2012. México: SEP. Recuperado de http://basica.sep.gob.mx/dgme/pdf/cominterna/ ProgramaSectorlal2007-2012.pdf

Sánchez, E. E. (2004). Comunicación y democracia. México: Instituto Federal Electoral Recuperado de http://www.ife.org.mx/docs/Internet/Biblioteca Virtual DECEYEC/deceyec DECEYEC/ Cuadernos Divulgacion DECEYEC/docs estaticos/cuaderno24.pdf

Savater, F. (2009). El valor de educar (4ª ed.). Barcelona: Ariel.

Sen, A. (2002). La democracia como valor universal. Recuperado de http://www.analitica.com/va/ economia/opinion/5192428.asp

Shulz, W., Ainley, J., Fraillon, J., Kerr, D. y Losito, B. (2010). Initial Findings from the IEA International Civic and Citizenship Education Study [Descubrimientos iniciales del estudio sobre Educación Cívica y Ciudadana del IEA]. Amsterdam: IEA.

Smith, M. K. (2001). Education for Democracy [Educación para la democracia]. Infed. Recuperado de http://www.infed.org/biblio/b-dem.htm 
URL: http://www.una.ac.cr/educare

CORREO: educare@una.cr

Tiana, A. (2008). La educación para la ciudadanía en España: Una nueva propuesta para la formación cívica de los jóvenes. En J. M. Valle (Coord.), Seminario de la identidad local a la ciudanía universal, el gran reto de la educación contemporánea (pp. 53-70). Madrid: UAM.

Torney-Purta, J., Lehmann, R., Oswald, H. y Shulz, W. (2001). Citizenship and Education in Twentyeigth Countries. Civic Knowledge and Engagement at Age Fourteen [Ciudadanía yeducación en veintiocho países: Estudio sobre conocimiento y compromiso a los catorce años]. Amsterdam: IEA.

Toro, J. B. (2007). Educación para la democracia. OEl. Recuperado de http://ww.oei.es/noticias/ spip.php?article563

UNESCO. (2000). Marco de acción de Dakar. Educación para todos: Cumplir nuestros compromisos comunes. Senegal: Foro Mundial sobre la Educación. Plaza de Fontoney, Francia: Autor. Recuperado de http://unesdoc.unesco.org/images/0012/001211/121147s.pdf

Uribe, M. T. (1995). Educación y sociedad. Maestros gestores de nuevos caminos. Medellín: Corporación Región.

Varona, E. J. (1981). Con el eslabón. La Habana: Editorial Letras Cubanas.

\section{Cómo citar este artículo en APA:}

Torres, A., Álvarez, N. y del Roble, M. (2013). La educación para una ciudadanía democrática en las instituciones educativas: Su abordaje sociopedagógico. Revista Electrónica Educare, 17(3), 151-172. Recuperado de http://www.revistas.una.ac.cr/index.php/EDUCARE/issue/current

Nota: Para citar este artículo en otros sistemas puede consultar el hipervínculo "Como citar el artículo" en la barra derecha de nuestro sitio web:

http://www.revistas.una.ac.cr/index.php/EDUCARE/index 